\title{
Exendin-4 Improves Yield and Function of Isolated Pre-Weaned Porcine Islets
}

\author{
Hien Lau ${ }^{1}$, Nicole Corrales ${ }^{1}$, Sarah Lee ${ }^{1}$, Jennifer Heng ${ }^{1}$, Kevin Zhang ${ }^{1}$, Michael Alexander ${ }^{1}$ and \\ Jonathan Robert Todd Lakey ${ }^{1,2, *}$ \\ ${ }^{1}$ Department of Surgery, University of California Irvine, Irvine, CA, United States \\ ${ }^{2}$ Department of Biomedical Engineering, University of California Irvine, Irvine, CA, United States
}

Received: August 21,2018; Accepted: August 28,2018; Published: September 04,2018

*Corresponding author : Jonathan Robert Todd Lakey, Department of Surgery and Biomedical Engineering, University of California Irvine, Irvine, CA, United States, 333 City Blvd West, Suite 1600, Orange, CA 92868, Tel: (949) 824-8022; Fax: (714) 938-0324;E-mail: jlakey@uci.edu

\section{Abstract}

Background: Porcine is lets have been proposed as an alternative islet source for islet transplantation in patients with type 1 diabetes. Our focus on pre-weaned porcine islets (4-11 days old; PPIs) has shown that this model of porcine islets is a cost effective and viable mean to isolate and culture islets for transplantation. Exendin-4 (Ex4) could improve islet viability, islet expansion, and insulin secretion. PPIs are immature after islet isolation and the addition of growth factors could accelerate their maturation. This study investigated the effects of exposure to Ex-4 on the maturation of freshly isolated PPIs during in vitro culture.

Methods: Pancreata from pre-weaned piglets (4-11 days old) were partially digested using low-dose collagenase and culture at $37^{\circ} \mathrm{C}$ and $5 \% \mathrm{CO} 2$ for up to 3 days. $10 \mathrm{nM}$ of Ex- 4 was added to culture media of freshly isolated PPIs. After 3-day culture, islets were assessed for islet yield, size, purity, membrane integrity, cellular viability and composition, and in vitro function.

Results: Islet count (IC) was significantly higher in the Ex-4 group than in the control group. Islets treated with Ex-4 were significantly smaller than islets from the control group. The percentages of major endocrine cells ( $\beta$-cells, $\alpha$-cells, and $\delta$-cells) were similar in both groups. Ex-4 supplementation significantly increased insulin secretion in response to glucose challenge.

Conclusions: The addition of Ex-4 to culture media of freshly isolated PPIs could improve islet counts and produce islets with enhanced glucose-stimulated function. Culturing PPIs in Ex-4 could be beneficial to improve islet quality before transplantation.

Keywords: Pre-weaned porcine islets; exendin-4; glucagon like peptide-1; diabetes

Abbreviations: PPIs : Pre-weaned porcine islets; Ex-4: exendin-4; GLP-: 1Glucagon like peptide-1; NPIs : Neonatal porcine islets

\section{Introduction}

Diabetes mellitus type 1 (T1DM) is an autoimmune disorder characterized by the gradual destruction of insulin-producing $\beta$-cells in the Islets of Langerhans [1]. Transplantation of insulinproducing islets has been demonstrated to be a promising cure to T1DM; however, the lack of healthy human donor Pancreata and inconsistent yields due to variable donor conditions and isolation techniques severely hampered the widespread clinical application of allotransplantation [2-3]. As the demand for islet transplantation worldwide increases, it is crucial to search for a suitable, non-human islet donor.

Porcine islets have been extensively studied with a huge potential to be a viable alternative source of islets for transplantation [4]. Porcine islets are suitable donors due to the ease of husbandry, unlimited supply, and similar physiology to human islets. Even though adult porcine islets can have immediate response to glucose challenge, the isolation process is difficult and costly with low yield due to the increased islet fragility [5]. Our group has demonstrated that islet isolation using pre-weaned piglets (4-11 days old) is inexpensive without the need of elaborated equipment and requires substantially less breeding time [6]. Pancreata from pre-weaned piglets also have higher yield and immature exocrine content [6-7]. Pre-weaned porcine islets (PPIs) have been demonstrated to have both in vitro and in vivo functions [8]. Despite these advantages, PPIs require prolonged culture and their functions are often delayed. Thus, efforts must be taken to reduce the latent period from isolation to functional islets, both in vitro and in vivo.

Glucagon like peptide-1 (GLP-1) is a 30 -amino acid peptide hormone secreted by the endocrine L-cells in the small intestine in response to meal intake [9]. The main functions of GLP-1 are to stimulate insulin secretion and inhibit glucagon secretion [10]. Short-term culture of fetal porcine islets in GLP-1 has been shown to improve both in vitro and in vivo glucose-stimulated insulin release and promote $\beta$-cell differentiation [11]. GLP-1 treatment prevented the gradual loss of insulin-positive cells and apoptosis, and enhanced in vitro response to glucose challenge in human islets [12]. Exendin-4, a long-lasting analog of GLP-1, offers similar functions to GLP-1 with a longer half-life [13]. Athymic nude rats treated with exendin- 4 for 10 days after transplantation of human fetal islet-like cell clusters demonstrated an increased c-peptide level in response to glucose challenge and $\beta$-cell mass in explanted graft [14]. A 2-day culture of human islets after isolation in exendin- 4 could restore $\beta$-cell function suppressed by Methylprednisolone treatment [15]. A recent study has shown that the addition of exendin- 4 and other growth factors 
to culture media of neonatal porcine islets (NPIs) could enhance the differentiation of endocrine cells, improve glucose stimulated insulin secretion and augment the ability to revert hyperglycemia in diabetic mice after 20 days of culture [16]. Whether PPIs are responsive to in vitro GLP-1/exendin-4 treatment has not been documented.

We hypothesized that PPIs are immature and their maturation into functional islets can be accelerated by in vitro treatment with exendin-4. The current study aimed to investigate the role of exendin-4 during short-term culture in the maturation of freshly isolated PPIs before transplantation.

\section{Materials and Methods}

\section{Islet Isolation}

Islets were isolated from 4-11-day-old, pre-weaned Yorkshire piglets (S\&S Farms, Ramona, CA) as previously described [6]. All animal procedures were performed with approval from the Institutional Animal Care and Use Committee (IACUC) at the University of California, Irvine. In brief, Pancreata were rapidly procured ( $\leq 10 \mathrm{mins}$ ) and placed in cold $\left(4^{\circ} \mathrm{C}\right)$ HBSS (cat\# 2402011, Gibco-Thermo Fisher Scientific, Waltham, MA) until enzymatic digestion. Cold ischemia was limited to less than 1 hour. Each pancreas was weighted and minced using 2 curved blunt/ blunt $18 \mathrm{~cm}$ Metzenbaum scissors (cat\# 14019-18, Fine Science Tools Inc., Foster City, CA) into $1 \mathrm{~mm} 3$ pieces, while 3 washes using cold $\left(4^{\circ} \mathrm{C}\right)$ HBSS were done in between to remove blood, connective tissue, fat, lymph nodes, etc. The minced tissues were digested using Sigma Type V Collagenase $(2.5 \mathrm{mg} / \mathrm{mL}$, dissolved in HBSS; cat\# C8051, Sigma-Aldrich, St. Louis, M0) in $100 \mathrm{rpm}$ shaking water bath at $37^{\circ} \mathrm{C}$ for 15 minutes. The digestion was stopped with HBSS supplemented with $1 \%$ porcine serum (cat\# 26250084, Gibco-Thermo Fisher Scientific, Waltham, MA). The digested tissues were filtered through a $500 \mu \mathrm{m}$ metal mesh.

\section{Islet Culture}

Isolated islet tissue clusters were cultured in a novel maturation media supplemented with $10 \%$ porcine serum in T-150 untreated suspension flask (cat \# CLS430825, Corning Inc., Corning, NY) at $37^{\circ} \mathrm{C}$ and $5 \% \mathrm{CO} 2$ humidified incubator (cat \# 3110, Thermo Forma Series II 3120 Water Jacketed CO2 Incubators, Carlsbad, CA) to allow islets to mature into complete islets. 10nM of exendin-4 (cat\# E7144, Sigma-Aldrich, St. Louis, MO) were added to the culture media in the experimental group ( $\mathrm{n}=8$ pancreas) while the control group ( $\mathrm{n}=12$ pancreas) was cultured in media without exendin-4. Islets were cultured for 3 days. Full media change was performed on day 1 and 3. Islets were collected for assessment at the end of culture.

\section{Islet assessment}

\section{Islet yield, size, purity, and membrane integrity}

Islet count (IC) and islet equivalent (IEQ) were determined by staining an aliquot of approximately 100 IEQ with $1 \mathrm{~mL}$ dithizone (DTZ; cat\# 150999, MP Biomedicals, Santa Ana, CA) for 5 minutes, and counted at $25 \mathrm{x}$ on a stereomicroscope (Max Erb, Santa Ynez, CA) with a 10x eyepiece graticule. The islet size ratio was calculated by dividing the IEQ (defined to be an islet with a diameter of $150 \mathrm{um}$ ) over the IC. The percentage of islet purity was calculated after DTZ staining by dividing the area of islets with positive DTZ staining over the total area of islets. Islet membrane integrity was analyzed by staining approximately 100 IEQ with calcein AM (cat\# C1430, Invitrogen, Carlsbad, CA) and propidium iodide (PI; cat\# P3566, Invitrogen, Carlsbad, CA) for 15 minutes. The stained islets were quantified using a Microplate reader (Infinite F200 Tecan, Männedorf, Switzerland). The membrane integrity percentage was calculated by the equation: calcein AM-positive cells/(calcein AM-positive cells + PI-positive cells) $\times 100$.

\section{Islet cellular composition}

The cellular composition of islets was determined by flow cytometry [17]. 5000 IEQ were washed twice with DPBS (cat\# 14190250, Thermo Fisher Scientific, Waltham, MA) and dissociated into a single cell suspension by incubating in Accutase (cat\# AT104-500, Innovative Cell Technologies, San Diego, CA) for 15 minutes in a $37^{\circ} \mathrm{C}, 100 \mathrm{rpm}$ shaking water bath. The cell suspension was filtered through a $40 \mu \mathrm{m}$ filter (cat \# 10199654, VWR, Visalia, CA) and stained with 7-aminoactinomycin D (7-AAD; cat\# A1310, Invitrogen, Carlsbad, CA) for 30 minutes on ice to detect live and dead cells. The cells were fixed in $4 \%$ paraformaldehyde for 10 minutes and permeabilized using Intracellular Staining Permeabilization Wash Buffer (cat\# 421002, BioLegend, San Diego, CA) for 15 minutes on ice. Permeabilized cells were incubated for 30 minutes on ice with Protein Block (cat\# ab64226, Abcam, Burlingame, CA) to reduce nonspecific binding followed by staining with fluorescently conjugated antibodies for intracellular markers in Intracellular Staining Permeabilization Wash Buffer (cat\#421002, BioLegend, San Diego, CA) supplemented with $1 \%$ bovine serum albumin (BSA; cat\# BAL62-0500, Equitech-Bio, Inc., Kerrville, TX) for 30 minutes on ice. PE conjugated anti-insulin (Anti-insulinPE; cat\# 8508, CST, Danvers, MA) was used as a marker for $\beta$-cells, APC conjugated anti-glucagon (Anti-glucagon-APC; cat\# NBP2-21803AF647, Novus Biological, Littleton, CO) was used as a marker for $\alpha$-cells, and PE conjugated anti-somatostatin (Anti-somatostatin-PE; cat\# NBP2-37447PE, Novus Biological, Littleton, CO) was used as a marker for $\delta$-cells. Cell populations were quantified using the NovoCyte 3000VYB Flow Cytometer (ACEA Biosciences, Inc., San Diego, CA) and analyzed using FlowJo software (FlowJo, Ashland, OR). An unstained, single-stained and matching isotype control were used as controls.

\section{Islet function}

Islet function was determined using glucose-stimulated insulin release assay [6]. 3 samples of 100 IEQ per isolation were incubated for 1 hour at $37^{\circ} \mathrm{C}$ and $5 \% \mathrm{CO} 2$ in media of low glucose (2.8 mm; L1), high glucose (28 mm; H), high glucose plus 3-isobutyl-1-methylxanthine $(28 \mathrm{~mm}+0.1 \mathrm{~mm}$ IBMX; H+), and again in low glucose $(2.8 \mathrm{~mm}$; L2). Insulin concentration was measured using a standard porcine insulin enzyme-linked immunosorbent assay (Porcine Insulin ELISA; cat\# 10-1200-01, Mercodia, Winston Salem, NC) and the absorbance was measured using a Microplate reader (Infinite F200, Tecan and Magellan V7, 
Männedorf, Switzerland). Secreted insulin concentration was normalized to ieqs. The stimulation index (SI) was calculated as the ratio of insulin concentration secreted in high glucose over the insulin concentration secreted in the first low glucose.

\section{Statistical Analysis}

All data are expressed as the mean \pm standard error of the mean (SEM). An unpaired t-test was performed to determine statistical significance. A p-value less than 0.05 was considered to be statistically significant and a $\mathrm{P}$ value less than 0.01 was considered to be highly statistically significant.

\section{Results}

Effects of exendin-4 treatment on PPI yield, size, purity, and membrane integrity

PPIs cultured in plain media without exendin-4 (control group) or media supplemented with exendin-4 (Ex-4) after islet isolation were stained with dithizone (DTZ) and counted on day 3 of culture. The islet counts (IC) per gram of pancreas tissue in the Ex-4 group were significantly higher than the control group (Ex-4 $=17613 \pm 1867 \mathrm{IC} / \mathrm{g}$, control = $11126 \pm 1568 \mathrm{IC} / \mathrm{g} ; \mathrm{p}<0.05)$ (Table 1). The islet equivalents (IEQ) per gram of pancreas tissue were not significantly different between the two groups ( $\mathrm{Ex}-4=11651$ $\pm 1375 \mathrm{IEQ} / \mathrm{g}$, control = $14753 \pm 2123 \mathrm{IEQ} / \mathrm{g}$; $\mathrm{p}>0.05$ ) (Table 1 ). Islets from the Ex-4 group was significantly smaller than islets in the control group as indicated by the ratio of IEQ/IC (Ex-4 = $0.76 \pm 0.11$, control $=1.60 \pm 0.2 ; \mathrm{p}<0.01$ ) (Table 1 ). The purity and membrane integrity measured by calcein AM-propidium iodide staining were not significantly different between the two groups (purity: Ex-4 = 78.4 $\pm 4.1 \%$, control $=80.2 \pm 2 \%$; $>0.05$; membrane integrity: Ex-4 $=86.6 \pm 4.5 \%$, control $=92.3 \pm 1.7 \%$; $\mathrm{p}>0.05$ ) (Table 1).

Table 1: Islet yield, purity, and viability of pre-weaned porcine islets after 3 days of culture in media with or without Exendin-4

\begin{tabular}{|c|c|c|c|c|c|}
\hline & IC/g & IEQ/g & IEQ/IC & Purity(\%) & Membrane Integrity(\%) \\
\hline Control & $11126 \pm 1568$ & $14753 \pm 2123$ & $1.60 \pm 0.2$ & $80.2 \pm 2$ \\
\hline EX-4 & $17613 \pm 1867^{*}$ & $11651 \pm 1375$ & $0.76 \pm 0.11^{* *}$ & $78.4 \pm 4.1$ \\
\hline
\end{tabular}

IC/g: Islet count per gram of pancreas tissue. IEQ/g: Islet equivalent per gram of tissue. Ex-4: Exendin-4. ${ }^{*}$ p<.05 versus control group. ${ }^{* *}$ p $<.01$ versus control group. Values represent mean \pm SEM.

A

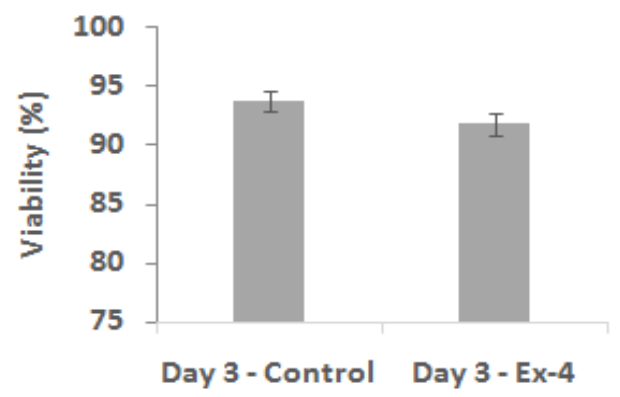

C

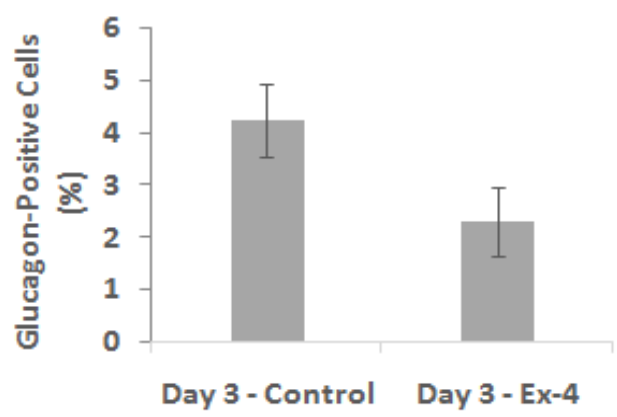

B

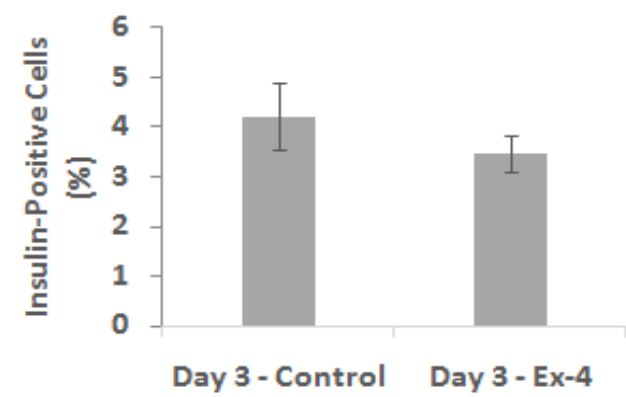

D

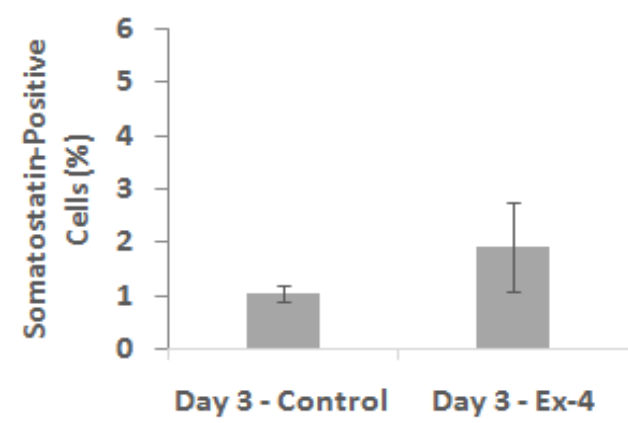

Figure 1: Flow cytometric analysis of pre-weaned porcine islets after 3 days of culture in media with or without Exendin-4. Islets were dissociated on day 3 of culture, stained with 7-AAD viability dye, anti-insulin, anti-glucagon, and anti-somatostatin antibodies, and analyzed by flow cytometry. Insulin, glucagon, and somatostatin gates were drawn after dead cells were excluded by 7-AAD viability staining. (A) Percent viability of pre-weaned porcine islet cells on day 3 of culture. (B) Percent of positive-insulin pre-weaned porcine islet cells on day 3 of culture. (C) Percent of positive-glucagon pre-weaned porcine islet cells on day 3 of culture. (D) Percent of positive-somatostatin pre-weaned porcine islet cells on day 3 of culture. Ex-4: Exendin-4. ${ }^{*} \mathrm{p}<0.05$ versus control group. ${ }^{* *} \mathrm{p}<0.01$ versus control group. Data shown as mean \pm SEM. 


\section{Effects of exendin-4 treatment on the cellular viability and composition of PPIs}

Cellular viability and composition were analyzed by FACS after islet dissociation. Similar to calcein AM-propidium iodide staining, 7-Aminoactinomycin D staining of islet cells show no significant differences in the viability between the control group and Ex-4 group (Ex-4 $=91.8 \pm 1 \%$, control $=93.7 \pm 0.8 \%$; $\mathrm{p}>0.05$ ) (Figure 1A). PPIs were dissociated into single cells and analyzed by flow cytometry to determine the effect of Ex-4 on the proliferation/differentiation of major endocrine cells after 3 days of culture. There were no significant differences in the percentages of insulin-, glucagon-, and somatostatin-positive cells between the control group and the Ex-4 group (insulinpositive cells: Ex- $4=3.5 \pm 0.4 \%$, control $=4.2 \pm 0.7 \%$; $>0.05$; glucagon-positive cells: Ex-4 $=2.3 \pm 0.7 \%$, control $=4.3 \pm 0.7 \%$; $\mathrm{p}>0.05$; somatostatin-positive cells: Ex- $4=1.9 \pm 0.8 \%$, control $=$ $1.1 \pm 0.1 \%$; $p>0.05$;) (Figure 1B, C, and D, respectively).

\section{Effects of exendin-4 treatment on the function of PPIs} in response to glucose challenge

Glucose stimulated insulin release assay was performed to evaluate the function of PPIs after 3-day culture. Islets were incubated in low glucose media (L1, 2.8mM), followed by high glucose media $(\mathrm{H}, 28 \mathrm{mM})$, then high glucose media with $0.1 \mathrm{mM}$ 3-isobutyl-1-methylxanthine $(\mathrm{H}+, 28 \mathrm{mM}+0.1 \mathrm{mM}$ IBMX), and finally to low glucose media again (L2) to determine whether islets can respond to glucose challenge in a physiological manner. Although the insulin concentration per IEQ released in L1 media was significantly lower in the Ex-4 group compared to the control group, islets from the Ex-4 group released significantly more insulin in both $\mathrm{H}$ and $\mathrm{H}+$ media (L1 media: Ex-4 $=0.00080 \pm$ $0.00013 \mathrm{ug} / \mathrm{IEQ}$ control $=0.0022 \pm 0.00057 \mathrm{ug} / \mathrm{IEQ} ; \mathrm{H}$ media: Ex-4 $=0.0056 \pm 0.0011 \mathrm{ug} / \mathrm{IEQ}$, control $=0.0027 \pm 0.00041 \mathrm{ug} /$ IEQ; $\mathrm{H}+$ media: $\mathrm{Ex}-4=0.011 \pm 0.0020 \mathrm{ug} / \mathrm{IEQ}$, control $=0.0054$ $\pm 0.0012 \mathrm{ug} / \mathrm{IEQ} ; \mathrm{p}<0.05$ ) (Figure $2 \mathrm{~A}$ ). However, no significant difference was found in the insulin concentration released in L2 media between the two groups (L2 media: Ex- $4=0.0085 \pm 0.0028$ ug/IEQ control $=0.0036 \pm 0.00075 \mathrm{ug} / \mathrm{IEQ} ; \mathrm{p}>0.05$ ) (Figure $2 \mathrm{~A}$ ). Islets treated with exendin-4 also had significantly higher response to glucose challenge as measured by the stimulation index ration $(\mathrm{Ex}-4=8.53 \pm 1.96$, control $=1.66+0.11 ; \mathrm{p}<0.01)$ (Figure 2B).

$\mathbf{A}$
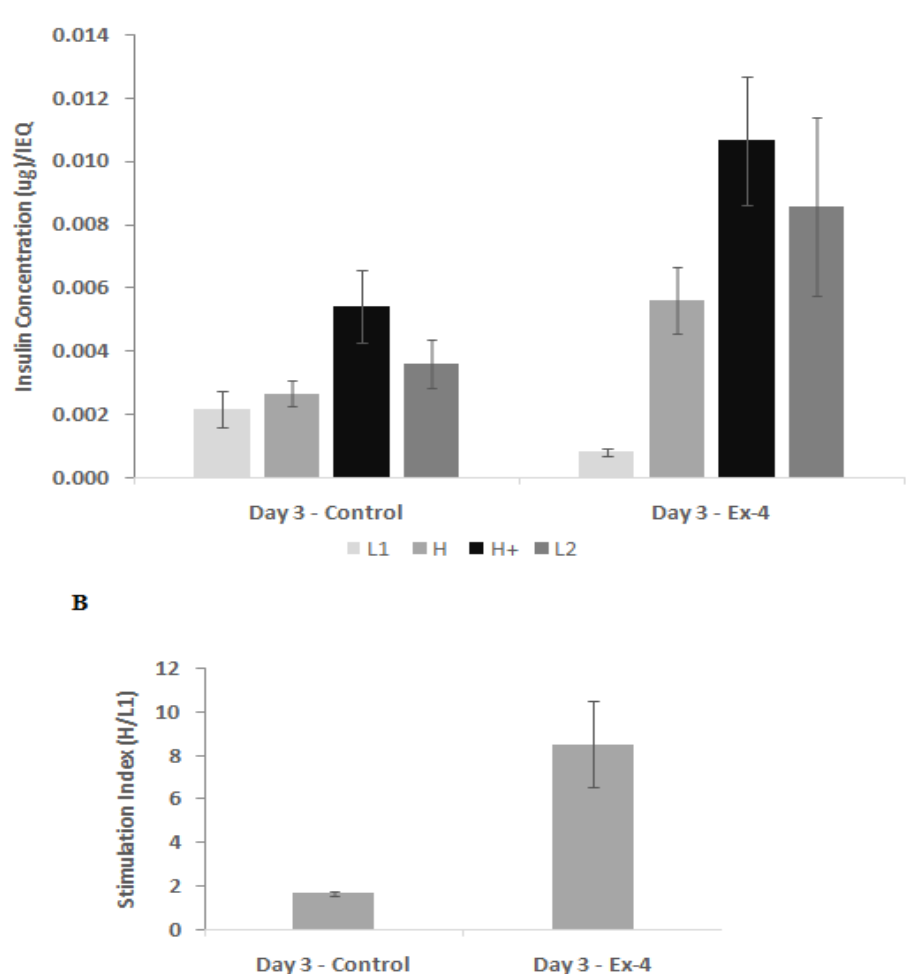

Figure 2: In vitro function of pre-weaned porcine islets after 3 days of culture in media with or without Exendin-4. In vitro function of islets was analyzed using glucose stimulated insulin release assay. Islets were incubated for 1 hour in media with the corresponding order of glucose concentration: $2.8 \mathrm{mM}(\mathrm{L} 1), 28 \mathrm{mM}(\mathrm{H}), 28 \mathrm{mM}+0.1 \mathrm{mM}$ IBMX (H+), and 2.8mM (L2) glucose media. The concentration of secreted insulin was measured by ELISA. Stimulation index (SI) was calculated as the ratio of H:L1. (A) Insulin concentration per IEQ (ug/IEQ) released by pre-weaned porcine islets cultured in media with or without Exendin-4 after incubation in varying concentration of glucose media. (B) Stimulation index of pre-weaned porcine islets cultured in media with or without Exendin-4. Ex-4: Exendin-4. ${ }^{*} \mathrm{p}<0.05$ versus control group. ${ }^{* *} p<0.01$ versus control group. Data shown as mean \pm SEM. 


\section{Discussion}

A major hurdle in the application of young porcine islets for xenotransplantation is the prolonged culture required for islets to exhibit glucose-stimulated function after isolation and the dormant period from transplantation to in vivo function. The reason for this has been suggested to be that young porcine islets are immature and often require a minimum of 7 days to have function [6]. Jimenez-Vera et al. have suggested that a 12day culture would be best for NPI function [18]. Lamb et al. and Krishnan et al. have reported that PPIs have improved glucose responsiveness and could revert hyperglycemia in diabetic mice after 7 -day culture $[6,8]$. Even though prolonged culture allows islets to mature as evidenced by the increase in insulin-positive cells and function, the number of islets recovered is markedly lowered [18]. Therefore, identifying potential treatments that could accelerate the maturation and function of young porcine islets would advance their application in clinical settings. Our results demonstrated the addition of exendin- 4 to culture media of freshly isolated PPIs significantly improves islet yield and produces smaller islets with enhanced function after 3 days of culture.

Islets experience considerable damages during cold ischemia and enzymatic digestion that could impact islet yield, viability, and function [19-21]. Exendin-4 has been demonstrated to have anti-apoptotic and improve islet survival after isolation [22]. Atsushi et al. have shown that culturing human islets with methylprednisolone and exendin- 4 for 48 hours after isolation could improve viable beta cell mass [15]. Even though our results showed that exendin-4 treated PPIs have similar viability to control islets, which might be due to the high viability in both groups ( $>90 \%$ viable), exendin- 4 treatment significantly improved the amount of islet recovered as indicated by the higher islet count. This effect could be due to the anti-apoptotic property of exendin-4; however, the exact mechanism remains to be investigated.

Exendin-4/GLP-1 treatment has been shown to have beneficial effects on the function of murine, rat, human and fetal porcine islets [11-12, 15, 23-24]. Human islets treated with exendin-4 for 48-hour during pre-transplant culture could improve insulin secretion compared to control islets or islets treated with methylprednisolone [15]. Farilla et al. have shown that the addition of GLP-1 to culture media of freshly isolated human islets has the most significant improvement in glucose induced insulin secretion after 3 days of culture [12]. Consistent with previous studies, our data confirmed that treatment of exendin-4 during 3-day culture enhanced the insulin secretory response of PPIs to glucose challenge.

Islet size can have a profound influence on islet function [2526]. Small rat islets (diameter $<125 \mathrm{um}$ ) are capable of releasing up to twice as much insulin in comparison to large islets (diameter $>150 \mathrm{um}$ ) [26]. In addition, transplantation of large rat islets could not revert hyperglycemia while small rat islets have an $80 \%$ cure rate at the same IEQ [27]. Similarly, Lehmann et al. have shown that smaller human islets (diameter $<150 \mathrm{um}$ ) produced approximately twice as much insulin during static and dynamic glucose challenge compared to large islets ( $>150 u m)$ [28]. The positive effect of exendin- 4 on the improved islet function could partially be attributed to the smaller islet size as indicated by the smaller IEQ/IC ratio.

Exposure of fetal porcine islets to GLP-1 could induce beta cell differentiation and proliferation, potentially account for the increase in glucose-stimulated insulin secretion and reversal of hyperglycemia in diabetic mice [11]. We found that exendin-4 supplementation in culture media did not induce endocrine cells in PPIs to differentiate or proliferate after 3 days of culture as the numbers of endocrine cells remained similar in both groups. Therefore, the increase in the ability of PPIs to response to glucose challenge could not be attributed to the proliferation or differentiation of beta cells. Movassat et al. have shown that exendin- 4 treatment at a similar dosage does not improve the numbers of insulin-positive cells after 4 days of culture, even though the PDX1- positive cells significantly increase [14]. Atsushi et al. have also reported that beta cell proliferation was not observed after freshly isolated human islets were cultured in exendin- 4 for 2 days [15]. Thus, the absence of beta cell growth after treatment of exendin- 4 could be due to the short culture time. In clinical settings, patients will potentially be receiving GLP-1 receptor agonist treatment after islet transplantation. Oral administration of exendin- 4 in diabetic mice transplanted with murine islet-like cell clusters could induce the growth of insulinpositive cells and enhance the graft function [24]. Therefore, exendin- 4 could potentially induce in vivo proliferation and/or differentiation of PPIs and improve islet graft function.

Our previous report suggested that PPIs should be cultured for at least 7 days to have adequate function, exendin- 4 treated PPIs could secrete insulin in a glucose-dependent manner only after 3 days of culture [8]. The results indicated that shortening the culture time to 3 days could improve the islet recovery by 2 folds [6]. Our in vitro function assay showed that control PPIs have a similar stimulation index to NPIs cultured in DMEM-F12 differentiation media containing exendin- 4 and growth factors (1.66 vs. 1.6, respectively) [16]. However, exendin-4 treated PPIs had comparable insulin secretion to adult porcine islets (the stimulation indices of both groups $=8.5$ ), suggesting that exendin- 4 treatment could augment the maturation of PPIs into functional islets [29].

\section{Conclusion}

In summary, our data have provided evidence to support the beneficial effects of in vitro exposure of PPIs to exendin-4, which could improve isletyield and produce smaller islets with enhanced insulin secretion in response to glucose challenge. These findings suggest that the addition of exendin-4 to PPI culture media may be useful during islet preparation before transplantation. Future studies evaluating the in vivo effects of exendin- 4 on the proliferation/differentiation and graft function of PPIs in diabetic animals will help to advance the clinical applications of exendin-4 and PPIs in islet transplantation.

\section{Acknowledgements}

This study was funded by the Juvenile Diabetes Research Foundation (JDRF Grant \#17-2013-288) and the Department of 
Surgery, University of California, Irvine, CA. The author would like to acknowledge the support from the Sue and Bill Gross Stem Cell Center, a California Institute of Regenerative Medicine (CIRM) supported facility, the Flow Cytometry Core - Institute for Immunology at UC Irvine, the Brownstein Family Foundation, and the PADRE Foundation.

\section{Declarations}

\section{Authorship}

HL and NC performed experiments, collated data, and wrote the manuscript. SL, JH, KZ performed experiments for the manuscript. MA and JL designed the study, reviewed data, and consented to final version of the manuscript.

\section{Conflict of Interest}

The authors declare no conflicts of interest associated with this manuscript.

\section{Ethical Approval}

All animal procedures were performed under approved protocols from the Institutional Animal Care and Use Committee (IACUC) at the University of California, Irvine, \#AUP-17-129.

\section{References}

1. Mathis D, Vence L, Benoist C. $\beta$-cell death during progression to diabetes. Nature. 2001;414(6865):792-798. Doi: 10.1038/414792a

2. Shapiro AM, Lakey JR, Ryan EA, Korbutt GS, Toth E, Warnock GL, et al. Islet transplantation in seven patients with type 1 diabetes mellitus using a glucocorticoid-free immunosuppressive regimen. The New England Journal of Medicine. 2000;343(4):230-238. Doi: 10.1056/NEJM200007273430401

3. Ricordi C, Tzakis AG, Carroll PB, Yijun Zeng, Horacio L, Rodriguez Rilo, et al. Human islet isolation and allotransplantation in 22 consecutive cases. Transplantation. 1992;53(2):407-414. Doi:10.1097/00007890-199202010-00027

4. Park CG, Bottino R, Hawthorne WJ. Current status of islet xenotransplantation. International Journal of Surgery. 2015;23:261266. Doi:10.1016/j.ijsu.2015.07.703

5. Dufrane D, D'hoore W, Goebbels RM, Saliez A, Guiot Y, Gianello P. Parameters favouring successful adult pig islet isolations for xenotransplantation in pig-to-primate models. Xenotransplantation. 2006;13(3):204-214 Doi: 10.1111/j.1399-3089.2006.00275.x

6. Lamb M, Laugenour K, Liang O, Alexander M, Foster CE, Lakey JRT. In vitro maturation of viable islets from partially digested Young Pig Pancreas. Cell Transplantation. 2014;23(3):263-272. Doi: 10.3727/096368912X662372

7. Krishnan R, Truong N, Gerges M, Stiewig M, Neel N, Ho-Nguyen K et al. Impact of donor age and weaning status on pancreatic exocrine and endocrine tissue maturation in pigs. Xenotransplantation. 2015;22(5):356-367. Doi: 10.1111/xen.12184

8. Krishnan R, Buder B, Alexander M, Foster CE, Lakey JR. Juvenile porcine islets can restore euglycemia in diabetic athymic nude mice after xenotransplantation. Transplantation. 2015;99(4):710-716. Doi: 10.1097/TP.0000000000000667
9. Holst JJ. The physiology of glucagon-like peptide 1. Physiological Reviews. 2007;87(4):1409-1439. Doi: 10.1152/physrev.00034.2006

10. Halden TAS, Egeland EJ, Åsberg A, Anders Hartmann, Karsten Midtvedt, Hassan Z. Khiabani, et al. GLP-1 restores altered insulin and glucagon secretion in posttransplantation diabetes. Diabetes Care. 2016;39(4):617-624. Doi: 10.2337/dc15-2383

11. Hardikar A, Wang XY, Williams LJ, Kwok J, Wong R, Yao M, et al. Functional maturation of fetal porcine beta-cells by glucagon-like peptide 1 and cholecystokinin. Endocrinology. 2002;143(9):35053514. Doi: 10.1210/en.2001-211344

12. Farilla L, Bulotta A, Hirshberg B, Li Calzi S, Khoury N, Noushmehr $\mathrm{H}$, et al. Glucagon-like peptide 1 inhibits cell apoptosis and improves glucose responsiveness of freshly isolated human islets. Endocrinology. 2013;144(12): 5149-5158. Doi: 10.1210/en.20030323

13. Deane AM, Chapman MJ, Horowitz M. The therapeutic potential of a venomous lizard: The use of glucagon-like peptide-1 analogues in the critically ill. Critical Care. 2010;14(5):1004. Doi: 10.1186/ cc9281

14. Movassat J, Beattie GM, Lopez AD, Hayek A. Exendin 4 up-regulates expression of PDX 1 and hastens differentiation and maturation of human fetal pancreatic cells. Journal of Clinical Endocrinology and Metabolism. 2002;87(10): 4775-4781. Doi: 10.1210/jc.2002-020137

15. Miki A, Ricordi C., Yamamoto T, Sakuma Y, Misawa R, Mita A, et al. Improved human islet preparations using glucocorticoid and exendin-4. Pancreas. 2014; 43(8): 1317-1322. Doi: 10.1097/ MPA.0000000000000184

16. Hassouna T, Seeberger KL, Salama B, Korbutt GS. Functional maturation and in vitro differentiation of neonatal porcine islet grafts. Transplantation. 2018. Doi: 10.1097/TP.0000000000002354

17. Ichii H, Miki A, Yamamoto T, Molano RD, Barker S, Mita A, et al. Characterization of pancreatic ductal cells in human islet preparations. Laboratory Investigation. 2008; 88(11):1167-1177. Doi: 10.1038/labinvest.2008.87

18.Jimenez-Vera E, Davies S, Phillips P, O'Connell PJ, Hawthorne WJ. Long-term cultured neonatal islet cell clusters demonstrate better outcomes for reversal of diabetes: In vivo and molecular profiles. 2015;22(2):114-123. Xenotransplantation. Doi: 10.1111/xen.12151

19. Contreras JL, Eckstein C, Smyth CA, Marty T. Sellers, Mario Vilatoba, Guadalupe B, et al. Brain Death Significantly Reduces Isolated Pancreatic Islet Yields and Functionality In Vitro and In Vivo after Transplantation in Rats. Diabetes. 2003;52(12):2935-2942. Doi: 10.2337/diabetes.52.12.2935

20.Pileggi A, Ribeiro MM, Hogan AR, Molano RD, Embury JE, Ichii $\mathrm{H}$, et al. Effects of Pancreas Cold Ischemia on Islet Function and Quality. Transplantation Proceedings. 2009;41(5):1808-1809. Doi: 10.1016/j.transproceed.2009.03.075

21.0mori K, Kobayashi E, Rawson J, Takahashi M, Mullen Y. Mechanisms of islet damage mediated by pancreas cold ischemia/ rewarming. Cryobiology. 2016; 73(2):126-134. Doi: 10.1016/j. cryobiol.2016.08.010

22. Farilla L, Bulotta A, Hirshberg B, Li Calzi S, Khoury N, Noushmehr $\mathrm{H}$, et al. Glucagon-Like Peptide 1 Inhibits Cell Apoptosis and Improves Glucose Responsiveness of Freshly Isolated Human Islets. 
Endocrinology. 2003;144(12):5149-5148. Doi: 10.1210/en.20030323

23.Peyot ML, Gray JP, Lamontagne J, et al. Glucagon-like peptide-1 induced signaling and insulin secretion do not drive fuel and energy metabolism in primary rodent pancreatic $\beta$-cells. PLoS ONE. 2009;4(7):e6221. Doi: 10.1371/journal.pone.0006221

24. Suen PM, Li K, Chan JCN, Leung PS. In vivo treatment with glucagon-like peptide 1 promotes the graft function of fetal isletlike cell clusters in transplanted mice. International Journal of Biochemistry and Cell Biology. 2006;38(5-6): 951-960. Doi: 10.1016/j.biocel.2005.08.005

25.Suszynski TM, Wilhelm JJ, Radosevich DM, et al. Islet size index as a predictor of outcomes in clinical islet autotransplantation. Transplantation. 2014; 97(12): 1286-1291. Doi: 10.1097/01. TP.0000441873.35383.1e
26. Fujita Y, Takita M, Shimoda M, Itoh T, Sugimoto K, Noguchi H et al. Large human islets secrete less insulin per islet equivalent than smaller islets in vitro. Islets. 2011;3(1):1-5. Doi: 10.4161/ isl.3.1.14131

27. MacGregor RR, Williams SJ, Tong PY, Kover K, Moore WV, StehnoBittel L. Small rat islets are superior to large islets in in vitro function and in transplantation outcomes. Am J Physiol Endocrinol Metab. 2006;290(5):E771-779. Doi: 10.1152/ajpendo.00097.2005

28.Lehmann R, Zuellig RA, Kugelmeier P, et al. Superiority of small islets in human islet transplantation. Diabetes. 2007;56(3):594603. Doi: 10.2337/db06-0779

29. Smith K, Purvis GW, Davis AM, et al. In vitro characterization of neonatal, juvenile, and adult porcine islet oxygen demand, $\beta$-cell function, and transcriptomes. Xenotransplantation. 2018. Doi: $10.1111 /$ xen.12432 